\title{
SEROPREVALENCE OF LEPTOSPIROSIS AMONG VETERINARY PROFESSIONALS IN TRICHY DISTRICT, TAMILNADU- AN OCCUPATIONAL HAZARD
}

\author{
G. Vazhavandal', B. Vallab Ganesh Bharatwaj', R. Jothiraj3, M. Ismail', P. Thirumalaikolundu Subramanian ${ }^{5}$, A. Uma ${ }^{6}$
}

${ }^{1}$ Associate Professor, Department of Microbiology, Chennai Medical College Hospital and Research Centre, Irungalur, Trichy, Tamilnadu. [The Tamilnadu Dr. M.G.R Medical University, Chennai]

${ }^{2}$ Laboratory Manager, Manipal Centre for Virus Research, Manipal University, Manipal, Karnataka

${ }^{3}$ Veterinary Surgeon, Chennai Medical College Hospital and Research Centre, Irungalur, Trichy, Tamilnadu.

[The Tamilnadu Dr. M.G.R Medical University, Chennai]

${ }^{4}$ Research Co-ordinator, Chennai Medical College Hospital and Research Centre, Irungalur, Trichy, Tamilnadu.

[The Tamilnadu Dr. M.G.R Medical University, Chennai]

5 Professor of Medicine, Chennai Medical College Hospital and Research Centre, Irungalur, Trichy, Tamilnadu.

[The Tamilnadu Dr. M.G.R Medical University, Chennai]

${ }^{6}$ Professor, Department of Microbiology, Chennai Medical College Hospital and Research Centre, Irungalur, Trichy, Tamilnadu.

[The Tamilnadu Dr. M.G.R Medical University, Chennai]

\section{ABSTRACT}

\section{BACKGROUND}

Leptospirosis is recognised as one of the commonest zoonotic infections in the world with a greatest occupational risk to agricultural workers, slaughterhouse workers, sewage workers, veterinarians and other professionals. To establish the prevalence of antibodies to leptospira in subjects at risk of exposure, the veterinary professionals including Veterinary Assistant Surgeons (VAS), Livestock Inspectors (LSI) and Animal Health Attendants (AHA) of Animal Husbandry Departments of Trichy district of Tamilnadu were selected for this study.

\section{MATERIALS AND METHODS}

Seroprevalence was determined by screening all the samples for antileptospira antibodies by Lepto IgM Microlisa (J. Mitra and Co.) and again confirmed by genus specific (non-pathogenic L. biflexa Patoc I strain) Microscopic Agglutination Test (MAT) at regional Leptospira Reference Centre, The Government KAPV Medical College, Trichy.

\section{RESULTS}

MAT detected $27 \%$ of seropositivity in veterinary professionals of Trichy District. Prevalence was also high in male having 0 - 5 years of occupational exposure and those who have attended abortion cases without wearing gloves during animal handling.

\section{CONCLUSION}

Leptospirosis is an occupational hazard. Awareness needs to be created among the risk population for the use of protective equipment and periodical screening for leptospirosis goes a long way in early detection and early intervention to reduce morbidity and mortality.

\section{KEYWORDS}

ELISA, Leptospira, MAT, Veterinary Professionals, Zoonotic Infection.

HOW TO CITE THIS ARTICLE: Vazhavandal G, Bharatwaj BVG, Jothiraj R, et al. Seroprevalence of leptospirosis among veterinary professionals in Trichy District, Tamilnadu- an occupational hazard. J. Evolution Med. Dent. Sci. 2017;6(29):2372-2376, DOI: $10.14260 /$ Jemds/2017/511

\section{BACKGROUND}

Leptospirosis is a widely prevalent zoonotic disease, caused by pathogenic spirochetes of the genus Leptospira. It infects both animals and humans. Over 20 serogroups and more than 250 serovars of Leptospira have been reported worldwide.

Financial or Other, Competing Interest: None.

Submission 04-03-2017, Peer Review 29-03-2017,

Acceptance 03-04-2017, Published 10-04-2017.

Corresponding Author:

Dr. Vazhavandal $G$,

Associate Professor,

Department of Microbiology,

Chennai Medical College

Hospital \& Research Centre,

Irungalur, Trichy,

Tamilnadu, India.

E-mail: hemarathinam2006@gmail.com

DOI: $10.14260 /$ jemds $/ 2017 / 511$
Leptospirosis is more common in areas that have a hot and humid climate. ${ }^{1}$ The cattle, goat, sheep, pigs, horse, Buffalos, rats, mice, shrews, hedgehogs and voles are confirmed as zoonotic foci for source of infection. ${ }^{2}$ Leptospirosis is considered as an occupational hazard for many people who work outdoors or with animals, for example farmers, veterinarians, abattoir workers, sewer workers, etc. ${ }^{3}$ The infected animals continuously shed leptospira along with urine. Leptospirosis is transmitted to humans through water contaminated with the urine of infected animals. ${ }^{4}$ The organisms enter through breaks in the skin, eyes or through mucous membranes. ${ }^{5}$ Leptospirosis is a disease of apparent to unapparent illness with non-specific presentations affecting multiple organs and causing death. ${ }^{6}$ In developing countries like India, laboratory diagnostic facilities and programmed, preventive control measures are very much limited. In India, very few states are having diagnostic and surveillance facilities. The symptoms of the disease range 
from mild flu to chronic multi-organ failure. Leptospirosis is always underdiagnosed even among risk population. ${ }^{7}$ Veterinary professionals handle all types of animals more frequently and the risk of getting leptospirosis is also more common. Study reports of leptospirosis among veterinary professionals are very few in Tamil Nadu; hence, this crosssectional study of seroprevalence of leptospirosis was taken up to know the current status among veterinary professional in Trichy district in Tamil Nadu.

\section{MATERIALS AND METHODS}

\section{Study Area and Design}

A cross-sectional study was carried out to assess the seroprevalence of leptospirosis among veterinary professionals in Trichy district.

Veterinary professionals of Trichy district comprised of viz. Veterinary Assistant Surgeons (33), Livestock Inspectors (29), Animal Health Attendants (79) of Animal Husbandry Departments. Of them samples were collected from 33 Veterinary Assistant Surgeons, 17 Livestock Inspectors and 6 Animal Health Attendants only from among those who attended the review meeting conducted on the day of study. This study was carried out after the approval of the Institutional Ethics Committee of this Medical College.

\section{Sample Collection}

A review day was selected to collect samples from all in one place and time. A brief sensitisation session was conducted to inform the symptoms of the disease, diagnosis, treatment, prevention and control aspects since the sample population was heterogeneous in nature. A pretest questionnaire was prepared and used to collect socio-demographic data viz. age, sex, residence, duration of service, occupational details, status of current and past history of illness and precautionary measures they adopt while handling the animals as appended in Annexure I.

\section{Inclusion Criteria}

Those attending clinics and handling animals are alone included in this study. Those who gave their consent alone were included in this study.

\section{Exclusion Criteria}

Those who are not attending clinics and were purely on administrative work were excluded in this study.

The study subjects comprised of 33 Veterinary Assistant Surgeons [VAS], 17 Livestock Inspectors [LSI] and 6 Animal Health Attendants [AHAS]. After collecting information in the case sheet, $5 \mathrm{~mL}$ of intravenous blood was collected with sterile precautions. All the serum samples were subjected to Lepto IgM ELISA test (J Mitra and Co.) as well as Microscopic Agglutination Tests [MAT] to detect antibodies to Leptospira, while antibody titre was measured by the genus specific Microscopic Agglutination Test (MAT) at the Regional Leptospira reference centre at The Government KAP Viswanathan Medical College, Trichy. ${ }^{8}$

\section{Microscopic Agglutination Test (MAT)}

The Microscopic Agglutination Test was performed after the baseline titre was done as per the guidelines given by the WHO manual on Leptospirosis and results were recorded and tabulated. ${ }^{8}$

The reading of each slide was determined in relation to the agglutination of the corresponding control antigen. Agglutinated leptospira form clumps, which are more or less dense and in which the movements of the free ends of the spirochete are visible. Every serum which gave an agglutination of at least $50 \%$ of the leptospires (as compared with the control antigen) was considered positive.

\section{RESULTS}

The study subjects were examined for any illness during sample collection and the results are shown in Table 1. Among the 56 veterinary professionals, only 14 (25\%) persons reported for some sort of illness.

The clinical symptoms during the study varied from prolonged fever (14.3\%), myalgia (35.7\%), muscular pain and sweating (28.6\%), migratory arthralgia (14.3\%) and anaemia (7.1\%); and none of them reported of current and past history of jaundice and uveitis. All the serum samples were analysed for the presence of leptospira antibody by ELISA as well as by MAT [Table 1].

\begin{tabular}{|c|c|c|c|c|c|}
\hline Sl. No. & Symptoms & $\begin{array}{c}\text { VAS } \\
(\%)\end{array}$ & $\begin{array}{c}\text { LSI } \\
(\%)\end{array}$ & AHAS (\%) & Total (\%) \\
\hline 1 & Prolonged fever & 0 & $1(7.1)$ & $1(7.1)$ & $2(14.3)$ \\
\hline 2 & Myalgia & $1(7.1)$ & $2(14.3)$ & $2(14.3)$ & $5(35.7)$ \\
\hline 3 & Muscular pain and sweating & $3(21.4)$ & 0 & $1(7.1)$ & $4(28.6)$ \\
\hline 4 & Migratory arthralgia & $1(7.1)$ & 0 & $1(7.1)$ & $2(14.3)$ \\
\hline 5 & Anaemia & $1(7.1)$ & 0 & 0 & $1(7.1)$ \\
\hline 6 & Jaundice & 0 & 0 & 0 & 0 \\
\hline $\mathbf{7}$ & Table 1. Clinical Symptoms Recorded during Blood Sample Collection from the Study Subjects \\
\hline
\end{tabular}

Figures in Parenthesis Denote Percentage

Out of the 56 serum samples, $6(10.7 \%)$ were positive by Lepto IgM Microlisa which comprised of 4 VAS and 2 AHA.
Fifteen (26.8\%) showed 50\% agglutination in 1:40 titre by MAT which comprised of 10 VAS, 3 AHAs, 2 LSIs. They were considered to have probable leptospirosis [Table 2]. 


\begin{tabular}{|c|c|c|c|c|c|c|c|c|}
\hline \multirow{2}{*}{ Subjects } & \multirow{2}{*}{ No. } & \multirow{2}{*}{ Male (\%) } & \multirow{2}{*}{ Female (\%) } & \multicolumn{2}{|c|}{ ELISA } & \multicolumn{3}{|c|}{ MAT Titre } \\
\hline & & & & Negative (\%) & \begin{tabular}{|l|} 
Positive (\%) \\
\end{tabular} & Negative (\%) & 20 & 40 \\
\hline VAS & 33 & 31 (55.3) & $2(3.6)$ & $29(51.8)$ & $4(7.1)$ & $21(37.5)$ & $\begin{array}{c}2 \\
(3.6)\end{array}$ & $\begin{array}{c}10 \\
(17.9)\end{array}$ \\
\hline AHA & 17 & $10(17.9)$ & 7 (12.5) & $15(26.8)$ & $2(3.6)$ & $10(17.9)$ & $4(7.1)$ & $3(5.4)$ \\
\hline LSI & 6 & $6(10.7)$ & 0 & $6(10.7)$ & 0 & $2(3.6)$ & $2(3.6)$ & $2(3.6)$ \\
\hline Total & 56 & $47(83.9)$ & $9(16.1)$ & $50(89.3)$ & $6(10.7)$ & $33(58.9)$ & $8(14.2)$ & $15(26.8)$ \\
\hline
\end{tabular}

\section{Figures in Parenthesis denote Percentage}

The laboratory tests showed that seropositivity was high in male professionals compared to females. Seropositivity was also associated with years of occupational exposure. The veterinary professionals having 0 - 5 years of working experience showed highest positivity by ELISA (83\%) and
MAT $(60 \%)$. There was no difference in seropositivity by ELISA between the veterinary professionals attending abortion case in animals from those who did not attend, but MAT showed difference in seropositivity between these two groups (67\% vs $33 \%)$. Veterinary professionals who did not wear gloves during animal examination showed higher seropositivity by both ELISA (67\%) and MAT (73\%) than glove wearers [Table 3].

\begin{tabular}{|c|c|c|c|c|c|c|}
\hline Sex & $\begin{array}{l}\text { Nos. } \\
(\%)\end{array}$ & $\begin{array}{c}\text { Elisa-Negative } \\
(\%)\end{array}$ & $\begin{array}{c}\text { Elisa-Positive } \\
(\%)\end{array}$ & $\begin{array}{l}\text { MAT- Neg } \\
(\%)\end{array}$ & $\begin{array}{c}\text { MAT-1:20 } \\
(\%)\end{array}$ & $\begin{array}{c}\text { MAT- 1:40 } \\
(\%)\end{array}$ \\
\hline Female & $9(16)$ & $8(14.3)$ & $1(1.8)$ & $4(7.1)$ & $3(5.36)$ & $2(3.6)$ \\
\hline Male & $47(84)$ & $42(75)$ & $5(8.9)$ & $29(51.8)$ & $5(8.9)$ & $13(23.2)$ \\
\hline Total & $56(100)$ & $50(89.3)$ & $6(10.7)$ & 33 (59) & $8(14.3)$ & $15(26.8)$ \\
\hline
\end{tabular}

\section{Figures in the Parenthesis denote Percentage}

None of these professionals met the case definition for a previous diagnosis of leptospirosis. There was no correlation between the past or present history of illness and the seropositivity.

\section{DISCUSSION}

This study presents a sero-surveillance of leptospirosis of a population of occupationally exposed veterinary professionals in Trichy district, Tamilnadu reporting a 27\% seroprevalence. This is in accordance with Trivedi TH et al and Shivakumar S showing 30\% - 50\% prevalence among high-risk groups. ${ }^{7,9}$ A study conducted by Swapna et al reported that $13.3 \%$ of prevalence in North Kerala. ${ }^{10}$

In our study, seropositivity was also high in male professionals (87\%) as compared to females (13\%). An association between prevalence of leptospirosis and gender has been reported in many studies. Particularly, men tend to present much higher incidence or prevalence of the disease than women, because they tend to work in high-risk jobs as per the findings of Lecour et al 1989; Ko et al 1999; Sasaki et al 1993; and Ciceroni et al 1995.7,11-14 However, this association has not been confirmed in other studies by Bertherat et al 1999; Kim 1987; Ratnam et al 1993.15-17

MAT detected leptospira antibodies in 15 (27\%) sera (1:40 titre). IgM ELISA detected leptospira antibodies in 6 (11\%) sera only. Out of the 6 ELISA positive samples 5 sera showed 1:40 titre, 1 showed 1:20 titre. Only 5 sera were positive by both ELISA and MAT. Unlike other human infections, the antibody response in leptospirosis does not follow the classical IgM and IgG pattern. The unusually long persistence of IgM antibodies and the differing abilities of the individuals to produce IgG antibodies are well documented. ${ }^{18}$
The discrepancy in the results of ELISA and MAT may be because of the use of only IgM ELISA, which is intended to detect only acute infections. The repeated occupational exposure may lead to chronic, subclinical infection and the individual may differ in eliciting $\operatorname{IgG}$ and $\operatorname{IgM}$ antibody response. Sometimes low titre is difficult to detect by ELISA. In this study, MAT detected more number of seropositivity, since MAT detects both IgM and IgG (current, recent and remote infection). MAT is used as the gold standard serological test, even though the test is very tedious and requires the maintenance of several leptospiral serovars in the laboratory. Also, the test requires an expert to read the results. However, MAT still remains the reference standard for serodiagnosis of Leptospirosis for the future. ${ }^{19}$ Even though ELISA is easy and rapid to perform, because of its low specificity and false negativity it can be considered as a screening test for leptospirosis in people with typical clinical presentation. ${ }^{10}$ As evident from the study of Swapna et al leptospiral IgM and IgG antibodies are both useful for seroprevalence studies of leptospirosis in high risk groups. ${ }^{10}$

Shivakumar $S$ reported that serosurvey in the asymptomatic high-risk group should be done with MAT only and a titre of $>1 / 50$ can be taken as cut-off titre and the genus specific tests are the tests of choice for the diagnosis of current infection. ${ }^{7}$ Moreover, considering the significant number of participants with false negative ELISA results, the actual seroprevalence of Leptospirosis is likely to be much higher. This reflects the alarming prevalence of Leptospirosis in high-risk groups and calls for early interventions to prevent further spread.

In our study, there was no correlation between the past or present history of illness and the seropositivity. Since Leptospirosis may present with a wide variety of non-specific clinical manifestations ranging from a mild flu-like illness to a serious and sometimes fatal disease. It also mimics many other diseases; they are therefore often not recognised as a 
feature of Leptospirosis. The diagnosis which is confirmed by laboratory tests is not always available, especially in developing countries. For these reasons, Leptospirosis is overlooked and underreported in many areas of the world. ${ }^{2}$ This may be the reason for the discrepancy in our study.

In this study, non-glove wearers showed highest seropositivity; however, occupational risk has been significantly decreased since preventive measures have been implemented. ${ }^{20}$

\section{CONCLUSION}

Understanding the epidemiology of this disease is a critical step for designing interventions, thereby diminishing the risk of transmission. Since animal infection is the source of human infections, study of animal leptospirosis is needed.

Human leptospirosis can be controlled by reducing its incidence in domestic and wild animals through vaccination and treatment of diseased animals. Sanitation, prevention of contact with contaminated environment or infected rodents can decrease the risk of infection. Occupational hygiene like wearing gloves and waterproof shoes is essential for preventing human leptospirosis. Appropriate drainage of wet areas is one of the most fundamental means of sanitation. More importantly, policy makers and public health officials should be convinced that addressing the principal conditions of poverty such as poor sanitation could lead to disease elimination. In conclusion, prevention is largely dependent on sanitation measures that are difficult to implement, especially in developing countries. The high-risk group such as veterinary professional should always use protective materials while handling animals and animal related materials.

\section{Limitations}

Serovar study was not attempted since our objective of the study was limited to the seroprevalence. Dark ground microscopy was not done for seropositives.

\section{ACKNOWLEDGEMENT}

Dr. Dhanapal Professor and Head of the Department of Microbiology and Mrs. Hema Neethipathi, Lab Technician from Department of Microbiology, The Govt. KAP Viswanathan Medical College, Trichy are gratefully acknowledged for supporting this study and help extended in performing MAT and Laboratory facilities. The authors gratefully acknowledge the Department of Animal Husbandry for mobilising their staff to collect serum samples.

\section{Annexure-1 \\ CASE SHEET}

(To accompany each sample collected from Veterinary assistant surgeon, LSI, AHAs)

Name of the Block:

Name of the Panchayat: Village:

Person Investigating: Date of Investigation:

Name:

Designation: Sample No: Lab No:

1. Name and Designation:

2. Name of the Father/Husband:

3. Age/Sex:

4. Complete Residential Address:

5. Name of Veterinary Dispensary/Sub Centre

a. No. of Years Working in the Dept. of $\mathrm{AH}$ :

6. Past Illness if Any:

Prolonged Fever/Chills/Myalgia/Jaundice/Muscular Pain and Sweating/Migratory Arthralgia/Anaemia

7. Recent Illness if any: Fever/Chills/Myalgia/Jaundice/Muscular Pain and Sweating/Migratory Arthralgia/Anaemia

8. Source of Drinking Water: Protected/Non-Protected

9. Did you attend any abortion case in animals recently- Yes/No; If yes, when?

10. Do you use gloves while examining the animals: always/at times/rarely/never

11. Eating of raw vegetables (salads) always/at times/rarely/never

12. 1. Any other information regarding your health (please specify)

2. Kindly mention the village where abortions are common in animals

\begin{tabular}{|c|c|c|c|c|c|}
\hline Sample & Date of Collection & Sample Code No. & $\begin{array}{c}\text { Condition of } \\
\text { Sample }\end{array}$ & Result & $\begin{array}{c}\text { Result } \\
\text { Communicated On }\end{array}$ \\
\hline
\end{tabular}

\section{REFERENCES}

[1] Rao SR, Gupta N, Bhalla P, et al. Leptospirosis in India and the rest of the world. Braz J Infect Dis 2003;7(3):178-93.

[2] Anon. Human leptospirosis: guidance for diagnosis, surveillance and control. WHO: Malta 2003:1-122.
[3] Thornley CN, Baker MG, Weinstein P, et al. Changing epidemiology of human leptospirosis in New Zealand. Epidemiol Infect 2002;128(1):29-36.

[4] Bharti AR, Nally JF, Ricaldi JN, et al. Leptospirosis: a zoonotic disease of global importance. Lancet Infect Dis 2003;3(12):757-71.

[5] Koutis CH. Special epidemiology. Editions, Technological educational institute of Athens. Athens, Greece 2007. 
[6] Vijayachari P, Sugunan AP, Shriram AN. Leptospirosis: an emerging global public health problem. J Biosci 2008;33(4):557-69.

[7] Shivakumar S. Leptospirosis-current scenario in India. In: Bichile SK (edr). API Medicine Update, Mumbai 2008:799-809.

[8] Faine S. Guidelines for the control of leptospirosis. World Health Organization: Geneva. WHO offset publication No. 67, 1982.

[9] Trivedi TH, Kamath SA. Leptospirosis: tropical to subtropical India. J Assoc Physicians India 2010;58:351-2.

[10] Swapna RN, Tuteja U, Nair L, et al. Seroprevalence of leptospirosis in high risk groups in Calicut, North Kerala, India. Indian Journal of Medical Microbiology 2006;24(4):349-52.

[11] Lecour H, Miranda M, Margo C, et al. Human leptospirosis-a review of 50 cases. Infection 1989;17(1):8-12.

[12] Ko AI, Reis GM, Dourado RCM, et al. Urban epidemic of severe leptospirosis in Brazil. Salvador leptospirosis study group. Lancet 1999;354(9181):820-5.

[13] Sasaki DM, Pang L, Minette HP, et al. Active surveillance and risk factors for leptospirosis in Hawaii. American journal of Tropical Medicine \& Hygiene 1993;48(1):35-43.
[14] Ciceroni L, Pinto A, Benedetti E, et al. Human leptospirosis in Italy, 1986-1993. European Journal of Epidemiology 1995;11(6):707-10.

[15] Bertherat E, Renaur A, Nabias R, et al. Leptospirosis and ebola virus infection in five gold-panning villages in northeastern Gabon. American Journal of Tropical Medicine and Hygiene 1999;60(4):610-5.

[16] Kim JS. Leptospirosis: a newly identified disease in Korea Asia. Pacific Journal of Public Health 1987;1:618.

[17] Ratnam S, Everard CO, Alex JC, et al. Prevalence of leptospiral agglutinins among conservancy workers in Madras city, India. Journal of Tropical Medicine and Hygiene 1993;96(1):41-5.

[18] Lupidi R, Cinco M, Delprete E, et al. Serological followup of patients involved in a localized outbreaks of leptospirosis. J Clin Microbiol 1991;29(4):805-9.

[19] Ooteman MC, Vago AR, Koury MC. Evaluation of MAT, IgM ELISA and PCR methods for the diagnosis of human leptospirosis. J of Microbiological Methods 2006;65(2):247-57.

[20] Waitkins SA. An update on leptospirosis. Communicable disease reputation 1984;44:3-4. 